\title{
A descriptive analysis of admissions to Amanuel Psychiatric Hospital in Ethiopia
}

\author{
Abebaw Fekadu ${ }^{1}$, Menelik Desta ${ }^{2}$, Atalay Alem³ ${ }^{3}$ Martin Prince ${ }^{1}$
}

\begin{abstract}
Background: The care of patients with severe mental disorder in Ethiopia remains centralized in the capital city. Objective: To assess pattern of psychiatric admission and its implication for service provision.

Methods: A descriptive analysis of one-year admission data was undertaken from the only psychiatric hospital in Ethiopia.

Results: The annual age-sex standardized admission rate was 4 per $100000(n=1564)$. Two-thirds of the patients came from Addis Ababa and the immediate surrounding areas. Nearly three-quarters were men, and aged 30 years or younger. Schizophrenia and bipolar disorder were the top two discharge diagnoses. The median length of hospital stay (LOS) was 63 days. Diagnosis of schizophrenia and place of residence, i.e. living outside of Addis Ababa independently predicted LOS above the median.

Conclusion: Admission data demonstrated a huge mental health unmet need in Ethiopia. Providing adequate resources for modernization and well-supervised decentralization may be vital steps in the quest for accessible and equitable psychiatric care. [Ethiop.J.Health Dev. 2007;21(2):173-178]
\end{abstract}

\section{Introduction}

The provision of adequate, fair and equitable care for patients in the developing world, particularly in subSaharan Africa is one of the greatest challenges of the $21^{\text {st }}$ century health system. The "unfinished agenda" of infectious diseases (1) remains a legitimate priority, but the burden from psychiatric disorders and other chronic diseases continues to grow unchecked. These concerns are compounded by un-moderated population growth, continuing economic constraints and unparalleled socioeconomic and geo-political changes.

Psychiatric disorders constitute four of the top ten causes of worldwide disease burden (2), yet remain lowest on the agenda of policy-makers, particularly in developing countries (3). Integrating psychiatric care into primary care, the principal strategy to address mental health unmet need, has remained inadequate and psychiatric services have been centralized in the large cities in subSaharan Africa. This is no different in Ethiopia, where the bulk of the care is provided by Amanuel hospital, the only psychiatric hospital in the country and located in Addis Ababa. The hospital provides extensive outpatient and a limited inpatient treatment service with 361 beds, mostly dedicated to acute care. Despite the development of several regional psychiatric units, there is evidence for limited use of services in the wider community. For example, in one of the largest ever community-based studies, conducted in southern-central Ethiopia, fewer than $10 \%$ of patients with schizophrenia and bipolar disorder had received psychiatric treatment $(4,5)$. There is one poorly equipped rehabilitation centre situated in an isolated location outside the capital city. There are no day care programmes or community services. Service user organizations have only begun recently.

Both presently and in the near future, the care provided by Amanuel hospital serves as an index of the level of psychiatric care in the country. We systematically describe admission patterns to Amanuel hospital based on the analysis of one-year admission record. In doing so, this study aimed to generate baseline data or information for current and future service provision.

\section{Methods}

Inpatient records held in each ward were used as a source of data. The detailed information recorded included socio-demographic and clinical data such as age, sex, address (place of residence), admission and discharge diagnoses, substance use, past history of admission, and medication received. Date of admission and discharge were also recorded and used to calculate length of hospital stay (LOS). Origins of patients were summarized into three groups based on approximate distance from the hospital: in Addis Ababa itself, "outlying" region (region within approximately $125 \mathrm{~km}$ of Addis Ababa), and "remote" region (region beyond $125 \mathrm{~km}$ of Addis Ababa). This classification is based on a pragmatic and evidence-based assumption of differential access to care relative to distance from a health service, in this case Amanuel hospital. A global clinical rating of outcome was recorded at discharge and categorized as follows: improved, unchanged, absconded and deceased. This rating was completed by either the senior ward nurse or the psychiatrist.

\footnotetext{
${ }^{1}$ Section of Epidemiology, Institute of Psychiatry, Health Services Research Department, King's College London, London, UK; ${ }^{2}$ Amanuel Specialised Mental Hospital, PO Box 1971, Addis Ababa, Ethiopia; ${ }^{3}$ Department of Psychiatry, Addis Ababa University, Addis Ababa, Ethiopia PO Box 9086, Telephone: 251 911218629; Fax: 251 115511079, E-Mail Address: Atalayalem@yahoo.com
} 
The lead consultant psychiatrist for each ward has primary responsibility for making a clinical diagnosis. Discharge diagnoses were preferred to admission diagnoses as a more valid and final categorization. For data analysis, discharge diagnoses were summarized into broad diagnostic classes according to the Diagnostic and Statistical Manual of Mental Disorders, $4^{\text {th }}$ revision (DSM-IV) (6). The DSM-IV is a diagnostic system used in clinical and research settings in many parts of the world, including Ethiopia.

Data were analyzed using the Statistical Package for Social Sciences, version 13 (SPSS, 13). Admission rate was standardized for age and sex using the national population as a standard based on the United Nation's estimate of the population of Ethiopia in 2000 (7). We assessed predictors of LOS using the logistic regression model to adjust odds ratios for potential confounding variables. LOS for the median or longer was included in the logistic model as the dependent variable. Age, gender, marital status, occupation, discharge diagnosis, history of previous admission, substance abuse, and distance from hospital were included in the model as independent variables.

\section{Results}

The annual age-sex standardized admission rate was 4 per 100000 population $(n=1564)$ with 6 per 100000 among men and 3 per 100000 among women with a comparative incidence figure of two. The admission rate was $100 \%$ higher for men.

Details of socio-demographic and clinical characteristics of patients are presented in Tables 1 and 2. Most patients were admitted for the first time (61.1\%), and were predominantly male $(72.4 \%)$, aged 30 years and under (69\%), single (70.2\%) and unemployed (54\%). The age of patients ranged from 12 to 90 years with a median age of 27. Patients under the age of 16 constituted $1.8 \%$ of admissions while those above 60 years of age constituted $0.7 \%$. Most patients came from Addis Ababa (unadjusted admission rate of 41 per 100000 , and 2 per 100000 for the rest of the country). The geographical distribution of residence of patients is illustrated with bipolar disorder in the Figure 1. Treatment during inpatient stay was subsidised for most (75.1\%) patients.

Schizophrenia was the most common discharge diagnosis (56.1\%) followed by bipolar disorder (20.6\%). Admission with psychotic disorder due to a general medical condition was not frequent (2.9\%). Similarly, substance-induced psychotic disorder was not common although $35.4 \%$ of patients had abused substances, mostly khat (locally known as chaat). No patient was admitted with anxiety disorders, and only 12 patients $(0.8 \%)$ had a discharge diagnosis of dysthymic disorder.
Table1: Socio-demographic characteristics of patients admitted to hospital, Addis Ababa, Ethiopia

\begin{tabular}{lll}
\hline Variables & Frequency & Percent \\
\hline $\begin{array}{l}\text { Total } \\
\text { Gender (n=1564) }\end{array}$ & 1564 & 100 \\
$\quad$ Male & 1132 & 72.4 \\
$\quad$ Female & 432 & 28.6 \\
$\begin{array}{l}\text { Age (n=1564) } \\
\quad 16\end{array}$ & & \\
$16-30$ & 28 & 1.8 \\
$31-50$ & 1051 & 67.2 \\
$>50$ & 445 & 28.5 \\
Marital status (n=1564) & 40 & 2.5 \\
$\quad$ Married & 345 & 22.1 \\
$\quad$ Single & 1098 & 70.2 \\
$\quad \begin{array}{l}\text { Post marital } \\
\text { Employment (n=1549) }\end{array}$ & 121 & 7.4 \\
$\quad$ Government employee & 201 & 12.9 \\
$\quad$ Farmer & 208 & 13.3 \\
$\quad$ Other employee & 296 & 19 \\
$\quad$ Unemployed & 844 & 54 \\
Address (n=1450) & & \\
$\quad$ Addis Ababa \\
$\quad$ Outlying areas & 664 & 45.8 \\
$\quad$ Remote & 344 & 23.7 \\
Pay status (n=1563) & 442 & 30.5 \\
$\quad$ Subsidized & & \\
$\quad$ Unsubsidised & 1174 & 75.1 \\
\hline$\quad$ & 389 & 24.9 \\
\hline
\end{tabular}

Table 2: Clinical profile of admitted patients, Addis Ababa, Ethiopia

\begin{tabular}{lll}
\hline Variables & Frequency & Percent \\
\hline $\begin{array}{l}\text { Diagnosis (n=1557) } \\
\quad \text { Schizophrenia }\end{array}$ & & \\
$\quad$ Brief and other psychotic & 758 & 56.1 \\
$\quad$ disorders & & 4.8 \\
$\quad$ Bipolar disorder & 322 & 20.6 \\
$\quad$ Major depression & 178 & 11.4 \\
$\quad$ Non-major depression & 12 & 0.8 \\
$\quad$ Psychotic disorder due to & 46 & 2.9 \\
$\quad$ general medical condition & & \\
$\quad$ Substance-induced psychosis & 46 & 2.9 \\
Use of substances (n=1407) & & \\
$\quad$ Khat & 215 & 15.3 \\
$\quad \begin{array}{l}\text { Alcohol } \\
\text { Khat and alcohol }\end{array}$ & 73 & 5.2 \\
$\quad$ None & 109 & 7.8 \\
Length of admission (in days) & 1010 & 71.8 \\
(n=1451) & & \\
$\quad$ Mean (SD) & & \\
$\quad$ Median & 85 & $(106.85)$ \\
$\quad$ Mode & 63 & $\mathrm{~N} / \mathrm{A}$ \\
$\quad$ Less than median & 60 & $\mathrm{~N} / \mathrm{A}$ \\
$\quad$ Median or longer & 685 & 52.8 \\
History of previous admission \\
(n=1558)
\end{tabular}




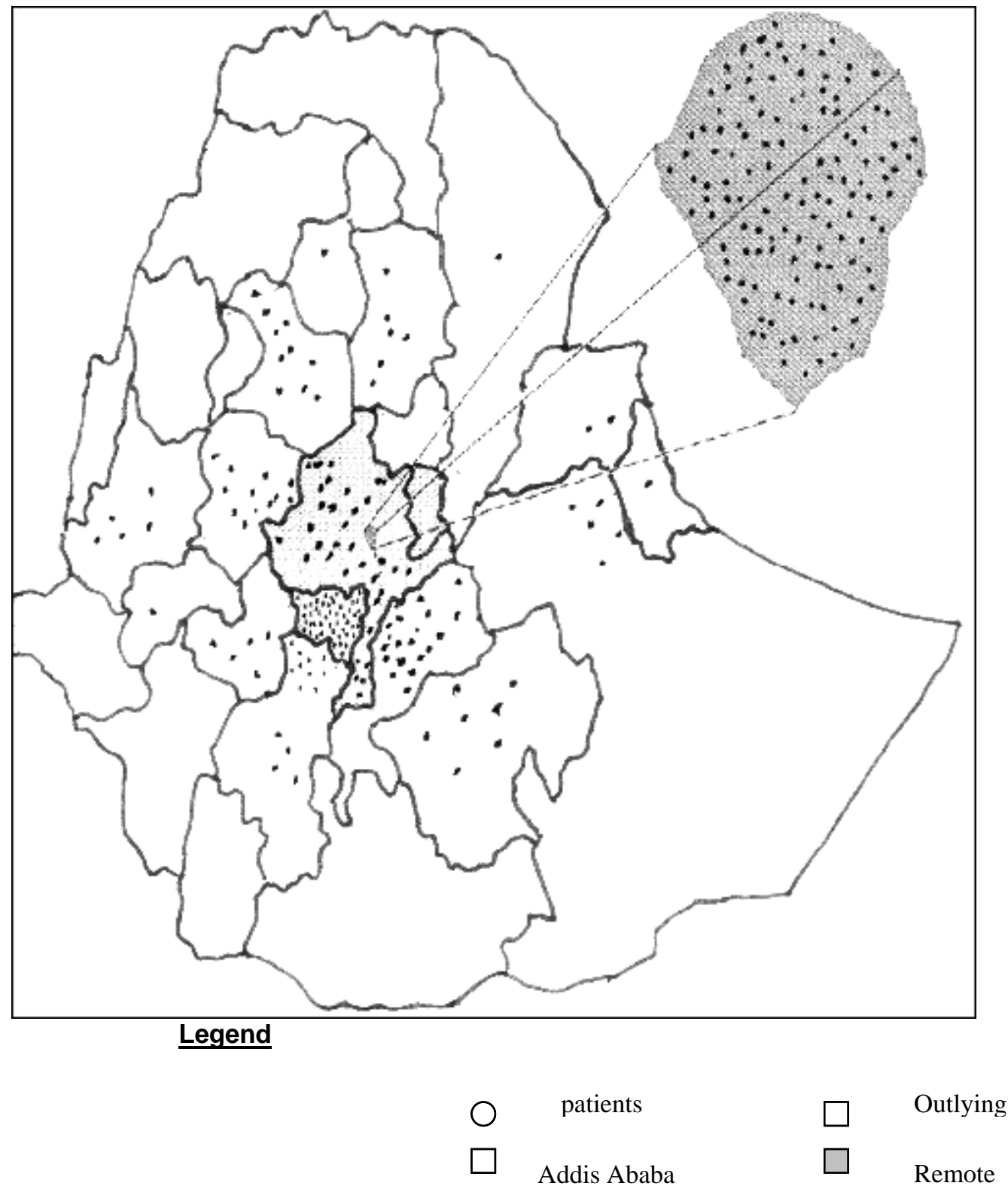

Figure 1: Geographic origin of patients admitted with bipolar disorder to Amanuel Hospital, Addis Ababa, Ethiopia

Based on the global clinical rating of outcome on discharge, about $91 \%$ of patients had improved, $4.2 \%$ (72) had absconded and $0.4 \%$ (7) was deceased, while only 3.5\% (55) of patients showed no change. The second outcome measure calculated from the data was length of hospital stay (LOS). The median LOS was 63 days. Only $4.1 \%$ of patients, predominantly with the diagnosis of schizophrenia, stayed in hospital for over 180 days. Discharge diagnosis of schizophrenia and address independently predicted duration of inpatient stay longer than the median LOS (Table 3). Thus, having a diagnosis of schizophrenia predicted a nearly two-fold increase in the risk of staying in hospital for 63 days or longer (OR=1.93; 95\% CI 1.28, 2.93). Coming from outside Addis Ababa, either from the immediate outlying region within $125 \mathrm{~km}(\mathrm{OR}=1.51$; 95\% CI 1.14, 2.00) or beyond $(\mathrm{OR}=1.36 ; 95 \% \mathrm{CI} 1.05,1.77)$ also predicted longer LOS. 
Table 3: Socio-demographic and clinical correlates of duration of admission for or above median length of duration, Addis Ababa, Ethiopia

\begin{tabular}{|c|c|c|c|c|c|}
\hline Variables & Number & Crude OR (95\% CI) & $\mathbf{P}$ & Adjusted OR (95\% Cl) & $\mathbf{P}$ \\
\hline \multicolumn{6}{|l|}{ Gender } \\
\hline Male & 932 & $1.07(0.84,1.35)$ & 0.69 & $1.21(0.90,1.63)$ & \\
\hline Female & 371 & 1.00 & ------ & 1.00 & \\
\hline \multicolumn{6}{|l|}{ Age } \\
\hline Under 16 & 25 & $2.50(0.87,7.22)$ & 0.09 & $2.11(0.69,6.45)$ & \\
\hline $16-30$ & 864 & $1.17(0.61,2.26)$ & 0.64 & $1.04(0.51,2.12)$ & \\
\hline $31-50$ & 380 & $1.29(0.66,2.53)$ & 0.46 & $1.12(0.55,2.30)$ & \\
\hline Above 50 & 34 & 1.00 & ------ & 1.00 & \\
\hline \multicolumn{6}{|l|}{ Marital status } \\
\hline Married & 301 & 1.00 & ------ & 1.00 & \\
\hline Never married & 901 & $1.01(0.79,1.31)$ & 0.92 & $0.93(0.68,1.28)$ & \\
\hline Post-marital & 101 & $0.77(0.52,1.16)$ & 0.21 & $0.72(0.45,1.15)$ & \\
\hline \multicolumn{6}{|l|}{ Occupation } \\
\hline Unemployed & 708 & $0.95(0.63,1.44)$ & 0.81 & $0.92(0.59,1.44)$ & \\
\hline Government employee & 157 & $1.05(0.72,1.51)$ & 0.81 & $1.08(0.72,1.62)$ & \\
\hline Other employee & 258 & $1.11(0.81,1.53)$ & 0.51 & $1.18(0.82,1.69)$ & \\
\hline Farmer & 180 & 1.00 & ------- & 1.00 & \\
\hline \multicolumn{6}{|l|}{ Address } \\
\hline In Addis Ababa & 596 & 1.00 & ----- & 1.00 & \\
\hline Outlying from Addis Ababa & 402 & $1.31(1.004,1.71)$ & .047 & $1.51(1.14,2.00)$ & 0.004 \\
\hline Remote from Addis Ababa & 305 & $1.19(0.93,1.53)$ & 0.16 & $1.36(1.05,1.77)$ & 0.019 \\
\hline \multicolumn{6}{|l|}{ Post admission } \\
\hline Yes & 404 & $0.96(0.77,1.19)$ & 0.70 & $0.95(0.75,1.21)$ & \\
\hline No & 839 & 1.00 & ------- & 1.00 & \\
\hline \multicolumn{6}{|l|}{ Diagnosis } \\
\hline Schizophrenia & 742 & $1.83(1.23,2.71)$ & 0.003 & $1.93(1.28,2.93)$ & 0.002 \\
\hline Major mood disorder & 452 & $1.23(0.82,1.85)$ & .267 & $1.27(0.83,1.96)$ & \\
\hline Other diagnosis & 109 & 1.00 & ------ & 1.00 & \\
\hline \multicolumn{6}{|l|}{ Substance } \\
\hline $\begin{array}{l}\text { Khat alone or with other } \\
\text { drugs }\end{array}$ & 268 & $0.94(0.72,1.23)$ & 0.67 & $0.88(0.65,1.18)$ & \\
\hline Other substances & 144 & $0.95(0.67,1.35)$ & 0.78 & $0.89(0.61,1.30)$ & \\
\hline None & 885 & 1.00 & ------ & 1.00 & \\
\hline
\end{tabular}

\section{Discussion}

This is the first systematic report on the pattern of psychiatric admissions in Ethiopia. It demonstrates a low population rate of admission with certain sociodemographic and clinical filters determining admission. Our findings also highlight inaccessibility of care as a potential target for intervention.

The admission rate in Ethiopia is much lower than reported in other parts of the world. For example, in the catchment area study in the Caribbean the inpatient treated prevalence of the population was 5 per 1000 population (8). The annual admission rate reported for England was similarly higher at 3.2 per 1000 population (9).The low rate of admission in Ethiopia clearly contrasts with the enormous need in the wider community as demonstrated by recent community-based studies in Ethiopia (4, 5, 10). Furthermore, among 370 patients attending Amanuel Hospital emergency clinic out of hours, beds were available for only $17.6 \%$ of patients identified as requiring inpatient care (Wakwoya, 2006, unpublished). Considering the overall magnitude and severity of these disorders and the lack of alternative treatment opportunities, the low rate of admission in
Ethiopia represents a profound neglect of patients and their care givers.

Most of the filters determining admission could be understood in terms of the expected socio-demographic characteristics of patients and nature of service. Thus, the predominance of patients under the age of 30 can be explained by predominance of patients with schizophrenia and bipolar disorder, both of which start early in life, and the clinicians' need to prioritise the available beds for those with severe disorders $(8,11)$. This predominance of patients with schizophrenia and bipolar disorder was seen among admitted patients in developed countries 60 years ago (12). In recent years, the commonest causes of admission in these countries are depression and anxiety disorders $(9,12,13)$. The changing pattern of admission in the developed world is partly due to the availability of beds (14). It also indicates that the service in Ethiopia may be lagging behind considerably. The lower proportion of patients admitted above the age of 60 years $(0.7 \%)$ is partly due to the low inception rate of psychotic disorders, the main causes of admission to hospital in this setting. Lack of appropriate resources, loss of care giver, death, leading to a 
proportionately low number of patients above the age of 60 , and neglect of older patients are some of the other potential reasons for the low figure. Admission of vulnerable young patients under the age of 16 into acute adult wards is clearly due to the lack of services dedicated for children and adolescents although they form $45 \%$ of the population (15). The care of the young and the elderly may be improved through integration of their care into general hospital care and possibly by establishing a limited number of specialized units.

Unlike in the national population data in which women are slightly overrepresented (15), most patients admitted were men, who were highly overrepresented among all diagnostic groups. This is particularly the case among those with schizophrenia. There is a small, albeit unlikely, possibility that this might be a true reflection of the prevalence of schizophrenia in the wider community. In one of the community studies mentioned above the male to female ratio was 5 to 1 (4). However, factors other than prevalence may explain the lower admission rate among women. These include quicker recovery, higher tolerance by care givers, higher mortality rate, lack of family support, and lesser economic power among women.

Most admitted patients had come from Addis Ababa, with a rate about 20 -fold higher than for the rest of the country. This is compatible with findings that demonstrate proximity to health facilities to be an important determinant of whether patients attend in emergency and during chronic illnesses (16).

According to the global clinical rating of outcome, the majority of patients have improved on discharge. However, this rating is not much informative and is of uncertain reliability. We used LOS as a more objective measure of outcome. Median LOS of 63 days at Amanuel Hospital is long and comparable to that reported in the 1970's in developed countries (17), where mean LOS in recent studies is two weeks or shorter (9, 13). Longer duration of hospital stay has not been demonstrated to be superior to shorter hospital stay in terms of reducing psychopathology, subsequent readmission or improvement in social adjustment (17, 18). On the other hand, short-term, especially planned admission may be more beneficial and less disruptive for patients and families (18). Thus, the long LOS at Amanuel is of no apparent benefit to patients or service providers. The predominance of patients with schizophrenia, one of the predictors of longer LOS, appears to be an important reason. LOS was further predicted by address; those coming outside Addis Ababa being more likely to stay in hospital longer. These patients are likely to come with severe and chronic untreated illness, which may in turn lead to slower treatment response. Making a safe discharge arrangement for these patients may also be more difficult compared to patients coming from Addis Ababa. In general, the lack of alternatives to inpatient care, absence of communitybased facilities, lack of arrangements to support families, and unavailability of effective rehabilitation services may further explain the long LOS.

Our findings demonstrate a low admission rate disproportionately represented by men, the young and those coming from Addis Ababa and its vicinity. Improved accessibility of care through careful and well supervised decentralisation, including integration with general hospitals, development of appropriate alternatives to hospital admission, such as day care and limited community-based services should be considered. Increasing the number of staff, engagement with patients and psycho-educational and supportive interventions with families may also help to improve care of patients and reduce LOS. The efficacy of these suggested interventions deserves further exploration.

\section{Acknowledgement}

We are very grateful to Ato Molla Ayele, senior psychiatry nurse at Amanuel Hospital for his assistance in data collection

\section{Reference}

1. Epping-Jordan J. Research to practice: International dissemination as evidence-based behavioural medicine. Ann Behav Med 2004;28:81-7.

2. World Health Organization. The World Health Report 2001. Mental Health: New understanding, new hope. Geneva: WHO; 2001.

3. Alem A. Community-based vs. hospital-based mental health care: the case of Africa. World Psychiatry 2002;1:98-9.

4. Kebede D, Alem A, Shibre T, Negash A, Fekadu A, Fekadu D et al. Onset and clinical course of schizophrenia in Butajira-Ethiopia. Soc Psychiatry Psychiatric Epidemiol 2003;38:625-31.

5. Negash A, Alem A, Kebede D, Deyessa N, Shibre T, Kullgren G. Prevalence and clinical characteristics of bipolar I disorder in Butajira, Ethiopia: a community-based study. J Affect Disord 2005;87:193-201.

6. American Psychiatric Association. Diagnostic and statistical manual of mental disorders, 4th Edition. Washington, DC: American Psychiatric Association, 1994.

7. United Nations Population Division. World population prospectus: The 2004 revision population database. 2004 [cited 13/01/2007]; Available from: http://esa.un.org/unpp/p2k0data.asp

8. Neehall J. An analysis of psychiatric inpatient admissions from a defined geographic cathcment area over a one-year period. West Indian Med J 1991;40:16-21.

9. Thompson A, Shaw M, Harrison G, Verne J, Ho D, Gunnell D. Patterns of hospital admission for adult 
psychiatric illness in England: analysis of hospital episode statistics data. $\mathrm{Br} \quad \mathrm{J}$ Psychiatry 2004;183:334-41.

10. Fekadu A, Shibre T, Alem A, Kebede D, Kebreab S, Negash A et al. Bipolar disorder among an isolated island community in Ethiopia. J Affect Disord 2004;80:1-10.

11. Avashti A, Khan M, Elroey A. Inpatient sociodemographic and diagnostic study from a psychiatric hospiatal in Libya. Int J Soc Psychiatry 1991;37:26779.

12. Martin B, Kedward H, Eastwood M. Hospitalization for mental illness: evaluation of admission trends from 1941 to 1971. Can Med Assoc J 1976;115:3225.

13. Levin A, Schlebusch L, Willgoose L, Naidoo N. Admissions to a South African general hospital psychiatric unit. Gen Hosp Psychiatry 1981;3:16570.
14. Fitzpatrick N, Thompson C. Acute mental health admissions in inner London: changes in patient characteristics and clinical admission thresholds between 1988 and 1998. Psychiatr Bull 2003;27:711.

15. World Health Organization. World Health Report 2005-Make every mother and child count. 2005 [cited 21/11/2006]; Available from: http://www.who.int/whr/2005/en

16. Hafner $\mathrm{H}$, An der Heiden W. Evaluative research in community psychiatry. Cambridge: Cambridge University Press, 1996.

17. Mattes JA. The optimal length of hospitalization for psychiatric patients: a review of the literature. Hosp Commun Psychiatry 1982;33:824-8.

18. Pfeiffer S, O'Malley D, Shott S. Factors associated with the outcome of adults treated in psychiatric hospitals: a synthesis of findings. Psychiatr Serv 1996;47:263-9. 